\title{
Antibacterial activity of phenolic extract of Spirulina platensis and its structural elucidation of bioactive compound
}

\author{
Hind M. A. El-Sayed*, Mohammed Rawway **, Nermine N. Abed***, \\ Rawhya A. Salah El Din*** \\ *Medical analysis specialist \\ ** Botany and Microbiology Department, Faculty of Science, Al-Azhar University \\ (Assiut) \\ ***Botany and Microbiology Department, Faculty of Science, Al-Azhar \\ University (Girls Branch)
}

\begin{abstract}
:
Spirulina as many other cyanobacteria species have the potential to produce a large number of antimicrobial substances, so they are considered as suitable organisms for exploitation as biocontrol agents of pathogenic bacteria. In the present study, antimicrobial activity of Spirulina platensis phenolic acid extract was investigated against pathogenic bacteria which cause sepsis in neonates. The algal extract was tested in vitro for their antibacterial effect against (Bacillus cereus, Enterococcus casseliflavus, Kocuria kristinae, Staphylococcus aureus, Alloiococcus otitis, Rosemonas gilardii, and Aeromonas hydrophila) using paper disc diffusion method and observed all these bacteria showed inhibition in growth by this extract. The bioactive components of Spirulina platensis have been assessed using GC-MS analysis. Eleven compounds in phenolic acid extract of the alga were identified. Bis(2-ethylhexyl) Phthatate (25.899\%), Palmitic acid (14.263\%) ,were the most prevailing compounds in phenolic acid extract.
\end{abstract}

Key words: Spirulina platensis, antibacterial activity, sepsis, paper-disc diffusion method, Gas chromatography-mass spectrometry (GC-MS) analysis.

\section{Introduction}

Neonatal sepsis continues to be a major cause of morbidity and mortality in the neonatal period. This is despite of improvement in antimicrobial therapy, advances in neonatal life support measures and the prompt recognition of perinatal risk factors for infection (Feigin and Cherry, 1992). 
Neonatal sepsis can be divided into early onset sepsis (EOS) and late onset sepsis (LOS) groups (Karambin and Zarkesh, 2011). There are different definitions for EOS, depending on the age at onset. Bacteremia and bacterial meningitis in less than 72 hour-old infants admitted to Neonatal Intensive Care Unit or in non-admitted infants aged less than 7 days are both grouped as EOS (Schuchat, 2000; Hornik et al., 2012; Edwards and Gonik, 2013). Organisms that cause EOS are usually already colonized in mothers' rectovaginal area and can infect amniotic fluid, placenta, cervix or vagina. These pathogens are likely to ascend during amniotic sac rupture or before the onset of childbirth and cause intra-amniotic infection ( $\operatorname{Rad}$ et al., 2016).

Spirulina is used for health food, feed and for the biochemical products since 1980s. In fact, Spirulina is the most concentrated and nutritious whole food known to science, Moreover Spirulina has got no side effects and is non-toxic in nature (Asghari et al., 2016). Spirulina platensis was also reported to present antimicrobial activity as well as to inhibit the replication of several viruses, such as Herpes simplex and HIV-1 (Pyne et al., 2017).

Spirulina was recommended by both National Aeronautics and Space Administration (NASA) and the European Space Agency (ESA) as one of the primary foods during long-term space missions. Spirulina has been orally administered to patients as an anti-cancer and anti-viral agent although the molecular mechanism by which Spirulina acts on the immune system remains largely undefined (Parages et al., 2012; Alam et al., 2013; Ismail et al., 2015). The present study aims to study in vitro antimicrobial activity of Spirulina platensis extract against pathogenic bacteria, which cause sepsis in neonates and separated and determined the most active component.

\section{Materials and Methods}

The study was a cross sectional one conducted on 50 neonates (age 0-28 days) with clinically suspected sepsis, who were admitted to the preterm unite in four hospitals in Sohag City, Egypt, namely, Sohag University Hospital (SUH), El helal Insurance Hospital (EIH), Life hospital (LH) and Lawfulness disassembly Hospital (LDH) and Some external intensive care units (ICU) in the centers, over a period of 18 months between March 2015 and August 2016. 
The blue green alga (Spirulina platensis) as powder used in the present study was provided by Prof. Dr. Rawhya Abd El Latif Salah El Din, Prof. of Phycology, Faculty of Science, Al-Azhar University. Isolated strains of newborn babie's blood are Bacillus cereus, Enterococcus casseliflavus, Kocuria kristinae, Staphylococcus aureus, Alloiococcus otitis and other coagulase-negative Staphylococci such as Staph. haemolyticus, Staph. Pseudintermedius. Other negative strains such as Rosemonas gilardii, Aeromonas hydrophila.

\section{Preparation of 24 hours pure culture}

A loop full of each of the purified microorganisms was suspended on $5 \mathrm{ml}$ of nutrient broth and incubated at $37^{\circ} \mathrm{C}$ for 24 hours (Black, 1999).

\section{Preparation of extract}

Phenolic compounds in Spirulina platensis were extracted as described by Mattila et al. (2005).

\section{Antimicrobial testing}

Antibacterial activity of the extract was assayed using the disc diffusion method (Bauer et al., 1996). For inoculums preparation and assay of antibacterial activity, nutrient agar was used. The bacteria were sub cultured and routinely maintained on nutrient agar. Antimicrobial activity was evaluated using the disc diffusion technique in petri dishes. Discs loaded with the extracting agents were tested as controls (Tuney et al., 2006).

\section{Chemical composition (GC-MS analysis)}

The aliquots were directly injected into gas chromatography-mass spectrometry (GC-MS) for analysis. The method was based on Hashimoto et al. (2001). The identification of the antimicrobial compounds was based on comparison of retention times and computer matching of the mass spectra with those of the National Institute of Standards and Technology (NIST) library and by direct comparison with published data. 


\section{Results and Discussion}

Spirulina extract was tested against eight pathogens bacteria. The results are summarized in Table (1). The zone of inhibition of Spirulina platensis extract against bacteria was ranged between $(7 \mathrm{~mm})$ to $(14 \mathrm{~mm})$. Spirulina extract showed antibacterial effect on wide range of bacteria and recorded highest zone of inhibition against Gram positive Cocci Staph. Pseudintermedius $(14.0 \mathrm{~mm})$ at concentration $100 \%,(11 \mathrm{~mm})$ at conc. $75 \%,(10 \mathrm{~mm})$ at conc. $50 \%$ and $(7 \mathrm{~mm})$ at conc. $25 \%$ followed by Bacillus cereus $(14.0 \mathrm{~mm})$ at conc. $100 \%$ and $(7.0 \mathrm{~mm}$ )at conc. $75 \%$ followed by Kocuria kristinae $(13 \mathrm{~mm})$ at conc. $100 \%$ and $(9.0$ $\mathrm{mm})$ at conc. $75 \%$ then Alloiococcus otitis $(11.0 \mathrm{~mm})$ at conc. $100 \%,(10 \mathrm{~mm})$ at conc. $75 \%,(9.0 \mathrm{~mm})$ at conc. $50 \%$ and $(8.0 \mathrm{~mm})$ at conc. $25 \%$ then Staph. aureus $(11.0 \mathrm{~mm})$ at conc. $100 \%$ and $(8.0 \mathrm{~mm})$ at conc. $75 \%$ then Enterococcus casseliflavus $(7.0 \mathrm{~mm})$ at conc. $100 \%$.

For Gram negative bacteria, the maximum zone of inhibition was recorded in phenolic crude extract of Spirulina platensis against Rosemonas gilardii (10.0 $\mathrm{mm})$ at conc. $100 \%,(7.5 \mathrm{~mm})$ at conc. $75 \%, 7.0 \mathrm{~mm}$ at conc. $50 \%$ followed by Aeromonas hydrophila $(7.5 \mathrm{~mm})$ at conc. 100 only.

Bloor and England (1991) reported that extracellular metabolites produced by Nostoc muscorum inhibited the growth of Bacillus circulans. Also, Austin (1992) showed that the supernatants and extracts derived from a commercial heterotrophically grown spray-dried preparation of Tetraselmissuecica (Chlorophyceae) were observed to inhibit Aeromonas hydrophila, A. salmonicida, Lactobacillus sp., Serratia liguefaciens, Staphylococcus epidermidis, Vibrio anguillillarum, V. salmonicida and Yersinia ruckeri type I.

Moreover, Kaushik and Chauhan (2008) reported that extracts of Spirulina platensis inhibited the growth of Staphylococcus aureus, Escherichia coli, Pseudomonas aeruginosa, Salmonella typhi and Klebsiella pneumoniae. They used hexane, ethyl acetate, dichloromethane and methanol to obtain the phenolic extracts and the methanolic extracts had the best results all this finding goes in harmony with the present investigation. 
Table 1: Inhibition of Microorganisms by phenolic acid extract.

\begin{tabular}{|c|c|c|c|c|}
\hline \multirow{2}{*}{ Test pathogen } & \multicolumn{4}{|c|}{ Zone of inhibition (mm) } \\
\hline & Conc.100\% & Conc. $75 \%$ & Conc.50\% & Conc. $25 \%$ \\
\hline Bacillus cereus & 14.0 & 7.0 & --- & --- \\
\hline Kocuria kristinae & 13.0 & 9.0 & $\begin{array}{ll}--- \\
\end{array}$ & $\begin{array}{ll}--- \\
\end{array}$ \\
\hline $\begin{array}{l}\text { Staphylococcus } \\
\text { pseudintermedius }\end{array}$ & 14.0 & 11.0 & 10.0 & 7.0 \\
\hline Alloiococcus otitis & 11.0 & $\mathbf{1 0 . 0}$ & 9.0 & 8.0 \\
\hline Rosemonas gilardii & $\mathbf{1 0 . 0}$ & 7.50 & 7.0 & $\begin{array}{ll}--- \\
\end{array}$ \\
\hline Staphylococcus aureus & 11.0 & 8.0 & $-\cdots$ & $-\cdots$ \\
\hline Aeromonas hydrophila & 7.50 & $-\cdots$ & $---\cdot$ & $-\cdots$ \\
\hline Enterococcus casseliflavus & 7.0 & --- & --- & --- \\
\hline
\end{tabular}

Although, the present investigation studied the antimicrobial activity of Spirulina against clinical isolates of Bacillus cereus, Kocuria kristinae, Staphylococcus Pseudintermedius, Alloiococcus otitis, Rosemonas gilardii, Staphylococcus aureus, Aeromonas hydrophila, Enterococcus casseliflavus and the finding from the present investigation is highly promising in view of the fact that the phenolic extract was successful inhibit the growth of the clinical isolates of the tested bacteria. Further research was carried out along this line may prove to be fruitful in bringing out a natural solution against these infection bacteria.

The present study reveals that the use of organic solvent such as ethyl acetate and methanol) in the preparation of Spirulina extraction and identified more compounds by GC-MS. From GC-MS analysis of solvent extracts of Spirulina, it was observed that ethyl acetate extract showed eleven components (Table 2 and Figure 1).

The most abundant compounds were Bis(2-ethylhexyl) Phthatate (25.899\%), Palmitic acid (14.263\%), 3-Hydroxy-Butanoic acid (10.795\%), Curan17-oic acid, 19-(acetyloxy)-2,16-didehydro-20-hydroxy-,methyl ester (5.732\%), Egyptian J. of Phycol. Vol. 18, 2017 
Hexadecanoic acid ethyl ester (5.720\%), Phenol-d5 (1.661\%), Methyl isoeugenol $2(0.463 \%), 3,5$-di-tert-butyl- phenol $(0.303 \%)$, 4-Tert-butyl-2,6, dinitro-phenol $(0.131 \%)$, Clemastine $(0.076 \%)$, Retalin $(0.050 \%)$ were also obtained as well as some biological activities are shown in Table (2).

In present study, Bis(2-ethylhexyl) Phthatate and Palmitic acid were identified in phenolic acid extract of Spirulina active compounds associated with the antibacterial properties. The maximum amount of Bis (2-ethylhexyl) Phthatate compound present is $(25.899 \%)$ which is responsible for antibacterial activity where exhibited strong cytotoxicity against human colon carcinoma cells. The DEHP is considered as pro inflammatory agent in other studies (Oie $\boldsymbol{e t ~ a l . , ~ 1 9 9 7 ; ~}$ Gourlay et al., 2003). It have antimicrobial activity against a number of Grampositive bacteria; Bacillus subtilis, Staphylococcus aureus and Streptococcus equosemens but the inhibition of Gram negative bacteria was lower; Escherichia coli, Pseudomonas aeruginosa and Closteridium perfringens. On the other hand, the compound has strong effect against $C$. albicans (Rowshanul and Rezaul, 2009).

Hexadecanoic acid methyl ester is also known as palmitic acid ester. The fatty acid being effective as antioxidant, pesticide, anti-androgenic, nematicide, flavoring agent, hypocholesterolemic and lubricant. Similarly, Gopalakrishnan and Vadivel (2011) and Vinay Kumar et al. (2011) reported the presence of hexadecanoic acid methyl ester in the methanol extract of Spirulina platensis and the ethanolic extract of Mussaenda frondosa, respectively.

In contrast to the above study, the present investigation reported Hexadecanoic acid ethyl ester in the phenolic acid extract of entire alga of Spirulina platensis. 


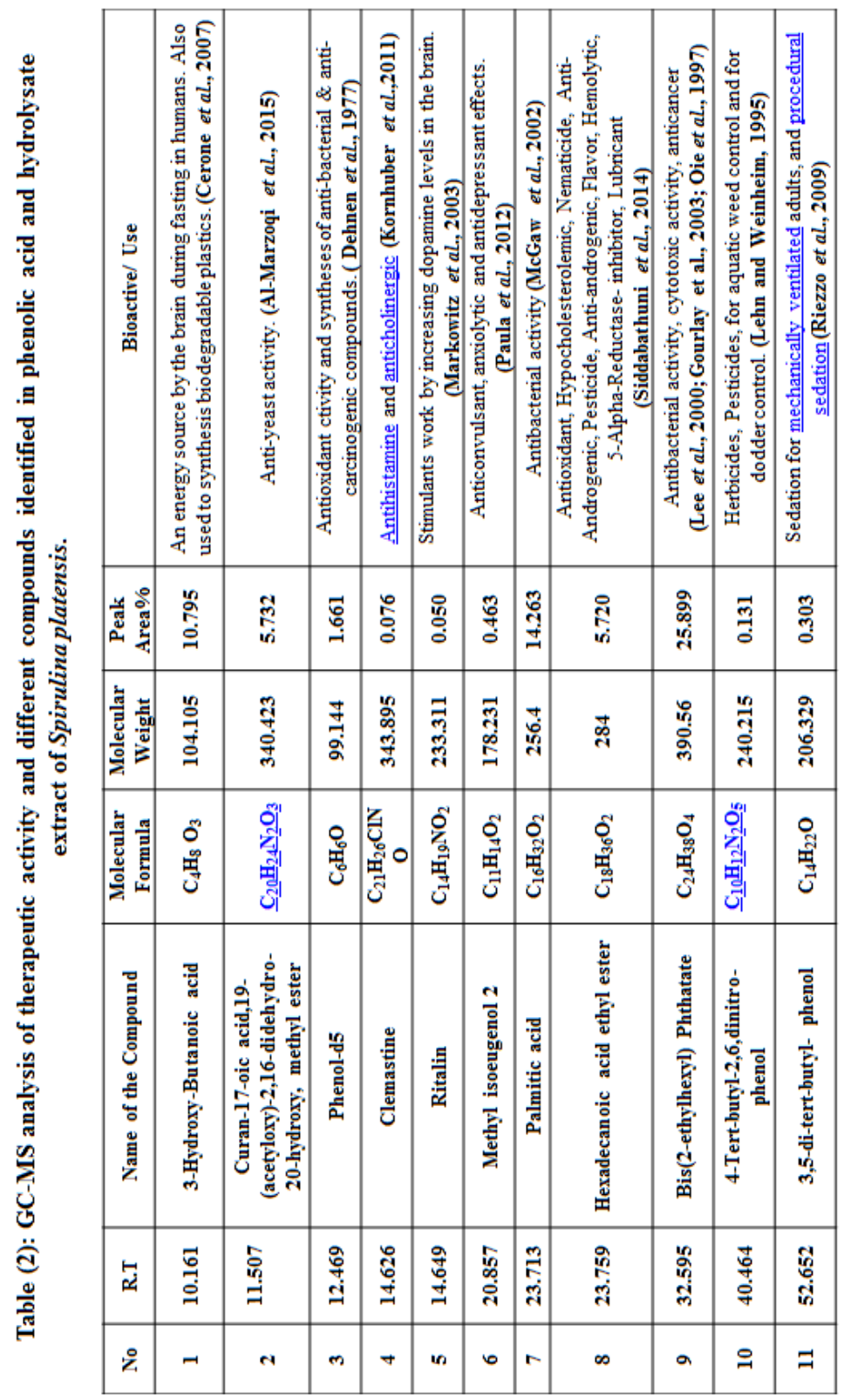




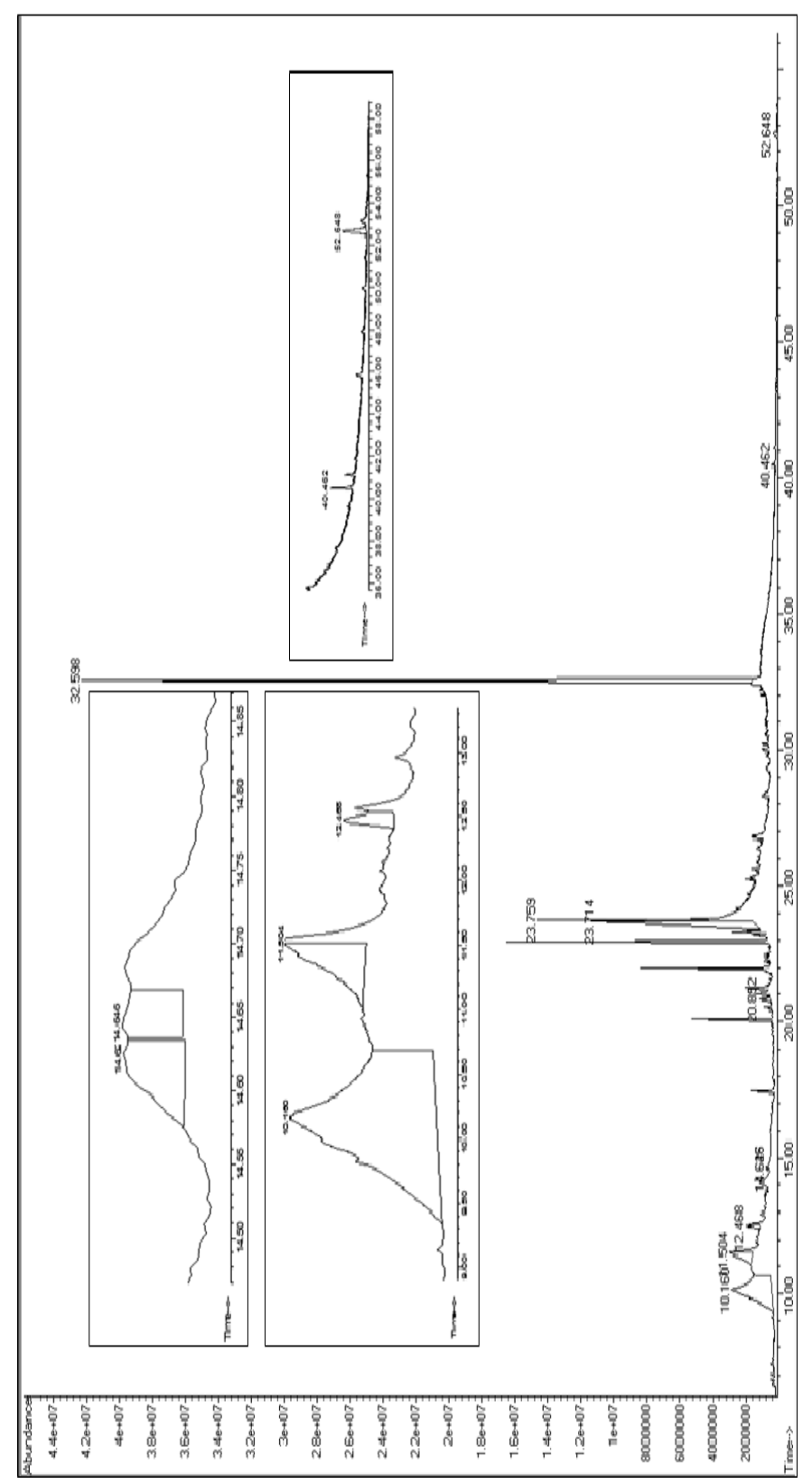

ป气

Egyptian J. of Phycol. Vol. 18, 2017

-52 - 
The antibacterial activity of algal compounds were extracted from algae depends upon the type of solvent used for extraction. The present study revealed that the use of organic solvents in the preparation of algal extracts provide more consistent antimicrobial activity. This observation clearly indicates that the polarity of antimicrobial compounds make them more readily extracted by organic solvents and using organic solvent does not negatively affect their bioactivity against antibacterial and antifungal species. Many investigations mentioned that the methanol extracts of

Nostoc muscorum revealed antibacterial activity on Sclerotinia sclerotiorum by Ishida et al. (1997). Also the methanolic extract of a blue green alga has been investigated by Kumar et al. (2006) for in vitro antimicrobial activity against Proteus vulgaris, Bacillus cereus, Escherichia coli, Pseudomonas aeruginosa, Aspergillus niger, Aspergillus flavus and Rhizopus nigricans using agar cup diffusion method. The antimicrobial activity of methanolic extract of $S$. platensis was also explained by Demule $\boldsymbol{e t}$ al. (1996) due to the presence of $\gamma$ Linolenic acid and compound was also present in the methanol extract. In the present study in phenolic acid extract found Bis(2-ethylhexyl) Phthatate, Palmitic acid, Phenol-d5, Clemastine and Hexadecanoic acid ethyl ester which have antimicrobial and cytotoxic activity, anti-inflammatory, anti-cancer, antihistaminic, antioxidant.

\section{References}

Alam, M.A.; Haider, N.; Ahmed, S.; Alam, M.T.; Azeez, A. and Perveen, A. (2013). Tahlab (Spirulina) And Few other Medicinal Plants Having AntiOxidant \& Immunomodulatory Properties Described In Unani MedicineA Review. Int. J. Pharm. Sci. Res., 4: 4158-4164.

Al-Marzoqi, A.H.; Hameed, I.H. and Idan, S. A. (2015). Analysis of bioactive chemical components of two medicinal plants (Coriandrum sativum and Melia azedarach) leaves using gas chromatography-mass spectrometry (GC-MS). Afr. J. Biotechnol., 14:2812-2830. 
Asghari, A.; Fazilati1, M.; Latifi, A.M. Salavati, H.and Choopani, A. (2016).A Review on Antioxidant Properties of Spirulina. Journal of Applied Biotechnology Reports, 3 (1): 345-351.

Austin, B., 1992. Inhibition of bacteria fish pathogens by Tetrasel missuecica. J. Fish Diseas., 15: 53-61.

Bauer, B.E. (1996). Amino- and carboxy-terminal domains of the yeast Rab escort protein are both required for binding of Y pt small G proteins. Mol. Biol. Cell.7:1521-33.

Black, J.G. (1999). "Microbiology": Principles and Explorations Marymount University.Wiley in New York.

Bloor, S. and England, R.R. (1991). Elucidation and optimization of the medium constituents controlling antibiotic production by the cyanobacterium Nostoc muscorum. Enzyme Microb. Technol., 13: 76-81.

Cerone, S.I.; Sansinanea, A.S. and García, M.C. (2007). Effects of betahydroxybutyric acid on bovine milk leukocytes function in vitro. Gen. Physiology Biophys., 26: 14-19.

Dehnen, W.; Pitz, R. and Tomingas, R. (1977). The mutagenicity of airborne particulate pollutants. Cancer Lett., 4: 5-12.

Demule, M.C.Z.; Decaire, G. Z. and Decano, M. S. (1996). Bioactive substances from Spirulina platensis. Int. J. Exp. Biol., 58: 93-96.

Edwards, M.S. and Gonik, B. (2013). Preventing the broad spectrum of perinatal morbidity and mortality through group B streptococcal vaccination. Vaccine. 31: 66-71.

Feigin, R.D. and Cherry, J.D. (1992).Text Book of Pediatric Infectious Disease. Saunders , Philadelphia, $\mathbf{1 1 0}$ - $\mathbf{1 5}$.

Gourlay, T.; Samartzis, I. ; Stefanou, D. and Taylor, K. (2003). Inflammatory response of rat and human neutrophils exposed to di-(2-ethyl-hexyl)phthalate plasticized polyvinyl chloride. Artificial Organs. 27: 256-260.

Gopalakrishnan, S. and Vadivel, E. (2011). GC-MS Analysis of Some Bioactive Constituents of Mussaenda frondosa Linn. International J. Pharm. and Bio Sciences. 2:313-320.

Hashimoto, K.; Urakami, K.; Fujiwara, Y.; Terada, S. and Watanabe, C. (2001). Determination of residual solvents in pharmaceuticals by thermal desorption-GC/MS, Analyt. Sci., 17: 645-648. 
Hornik, C. P.; Fort. P. and Clark, R. H. (2012). Early and late onset sepsis in very-low-birth-weight infants from a large group of neonatal intensive care units. Early Human Develop., 88: 69-74.

Ishida, K.; Matsuda, H.; Murakami, M. and Yamaguchi, K. (1997). Kawaguchipeptin B. and antibacterial cyclic undecapeptide from the cyanobacterium Microcystis aeruginosa. J. Nat. Prod., 60: 724-726.

Ismail, M.; Hossain, M.F.; Tanu, A.R. and Shekhar, H. U. (2015). Effect of spirulina intervention on oxidative stress, antioxidant status, and lipid profile in chronic obstructive pulmonary disease patients. BioMed. Res. Int., 7-15.

Karambin, M. and Zarkesh, M. (2011). Entrobacter the most common pathogen of neonatal septicemia in Rasht, Iran. Iran J. Pediatr., 21: 83-7.

Kaushik, P. and Chauhan, A. (2008). In vitroantibacterial activity of laboratory grown culture of Spirulina platensis. Ind. J. Med. Microbiol., $48:$ 348-52.

Kornhuber, J.; Muehlbacher, M.; Trapp, S.; Pechmann, S.; Friedl, A.; Reichel, M.; Mühle. C.; Terfloth, L.; Groemer, T.; Spitzer G.; Liedl, K.; Gulbins, E. and Tripal, P. (2011). "Identification of Novel Functional Inhibitors of Acid Sphingomyelinase". PLOS ONE. 6 (8): e23852.

Kumar, P.; Angadi, S. and Vidyasagar, G. (2006). Antimicrobial activity of blue green and green algae. Ind. J. Pharm. Sci., 68: 647-648.

Lee, K. H.; Kim, J. H. ; Lim, D. S. and Kim, C. H. (2000). Anti-leukemic and anti-mutagenic effects of di-(2-ethylhexyl) phthalate isolated from Aloe vera Linne. J. Pharm. Pharmacol., 52: 593-598.

Lehn, J. M. and Weinheim, V.C.H. (1995). "Supramolecular Chemistry Concepts and Perspectives". BRIDGES, Collège de France, 11, Place Marcelin Berthelot, Paris.

Markowitz, J. S.; Straughn, A. B. and Patrick, K. S. (2003). "Advances in the pharmacotherapy of attention-deficit-hyperactivity disorder: focus on methylphenidate formulations". Pharmacotherapy. 23 : 1281-99. 
Mattila, J.; Omelyanchuk, L.; Kyttala, S.; Turunen, H. and Nokkala, S. (2005). Role of Jun N-terminal Kinase (JNK) signaling in the wound healing and regeneration of a Drosophila melanogaster wing imaginal disc. Int. J. Develop. Biol., 49: 391-399.

McGaw, L. J.; Jäger, A.K. and Van Staden, J. (2002). Isolation of antibacterial fatty acids from Schotia brachypetala. Fitoter., 73:431-433.

Oie, L.; Hersoug, L.G. and Madsen, J. O. (1997). Residential exposure to plasticizers and its possible role in the pathogenesis of asthma. Environ. Health Perspect., 105: 972-978.

Parages, M. L.; Rico, R. M.; Abdala-Díaz, R. T.; Chabrillón, M.; Sotiroudis, T. G. and Jiménez, C. (2012). Acidic polysaccharides of Arthrospira (Spirulina) platensis induce the synthesis of TNF- $\alpha$ in RAW macrophages. J. Appl. Phycol., 24: 1537-1546.

Paula, J. A. M.; Silva, M. R. R.andCosta, M. P. (2012). Evidence-Based Complementary and Alternative Medicine. 420715. Peer-reviewed journal,Hindawi Publishing Corporation.

Pyne, S.K.; Bhattacharjee, P. and Srivastav, P.P. (2017). Microalgae (Spirulina platensis) and Its Bioactive Molecules: Review. Indian Journal of Nutrition, 4 (2): 2395-2326.

Rad, Z.A.; Mojaveri , M. H.; Esmaeilzadeh, S.; Firouzjahi, A.; Laegh, M.; Khafri, S. and Rad, M. N. (2016).Colonization of rectovaginal Escherichia coli and group B streptococci in mothers and on infants' body surface and their related risk factors. Caspian Journal of Pediatrics, 2 (2): 148-52.

Riezzo, I.; Centini, F.; Neri, M.; Rossi. G.; Spanoudaki, E.; Turillazzi, E. and Fineschi, V. (2009). "Brugada-like EKG pattern and myocardial effects in a chronic propofol abuser". Clin. Toxicol., 47: 358-63.

Rowshanul, M. and Rezaul, M. (2009). Antimicrobial and Cytotoxic Activity of Di-(2-ethylhexyl) Phthalate and Anhydrosophoradiol- 3-acetate Isolated from Calotropis gigantea (Linn.) flower. Mycobiol., 37: 31-36.

Schuchat, A. (2000). Neonatal group B streptococcal diseasescreening and prevention. New Eng. J. Med., 343: 209-10. 
Siddabathuni, A.; Akalanka, D. and Somnath, D. (2014). Gas Chromatography-Mass Spectrometry Analysis of Kyllinga Triceps. IJPSR, 5: 2999-3003.

Tuney, I.; Cadirci, B. H.; Unal, D. and Sukatar, A. (2006). Antimicrobial activities of the extracts of marine algae from the coast of Urla (Izmir, Turkey). Turk. J. Biol., 30: 171-175.

Vinay, A. K.; Bhatnagar, J.; Srivastava, J. N. (2011). Antibacterial activity of crude extracts of Spirulina platensis and its structural elucidation of bioactive compound. J. Med.l Plants Res., 5:7043-7048.

\section{النشاط المضاد للبكتريا لمستخلص الفينول لطحلب Spirulina platensis وفصل

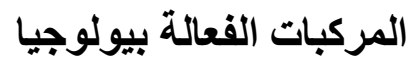

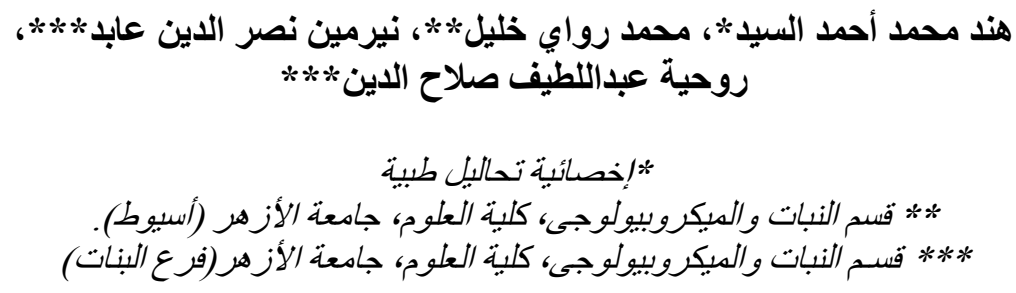

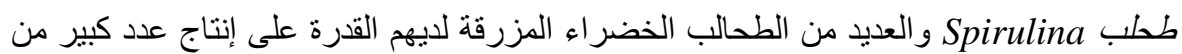

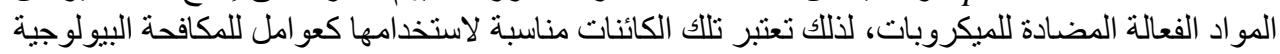

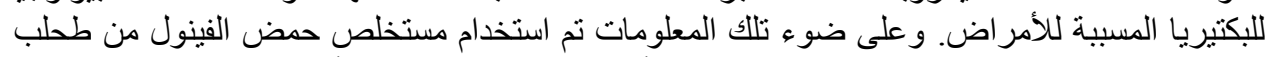
SPirulina platensis

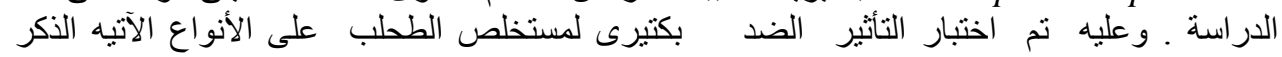
(Bacillus cereus, Enterococcus casseliflavus, Kocuria kristinae, Staphylococcus aureus, Alloiococcus otitis, Rosemonas gilardii, and Aeromonas hydrophila)

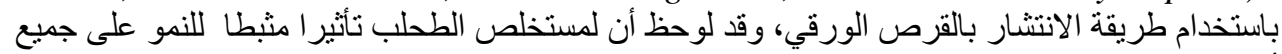

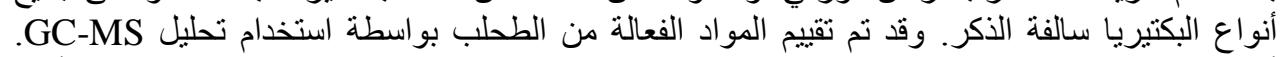

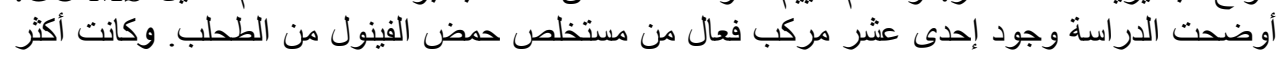

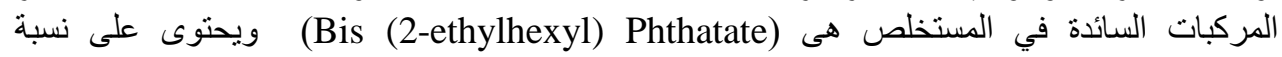

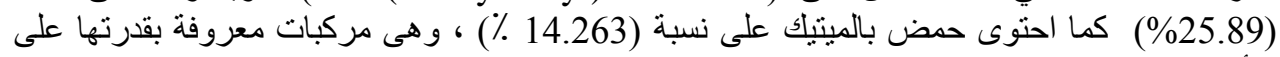

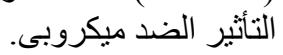

